\title{
Effect of Breakdown Behavior of Passive Films on the Electrochemical Jet Milling of Titanium Alloy TC4 in Sodium Nitrate Solution
}

\author{
Yuanyuan Wang ${ }^{1}$, Ningsong $Q u^{1,2, *}$ \\ ${ }^{1}$ College of Mechanical and Electrical Engineering, Nanjing University of Aeronautics and \\ Astronautics, Nanjing 210016, China \\ ${ }^{2}$ Jiangsu Key Laboratory of Precision and Micro-Manufacturing Technology, Nanjing 210016, China \\ *E-mail: $\underline{\text { nsqu@ @nuaa.edu.cn }}$
}

doi: $10.20964 / 2019.02 .05$

Received: 2 August 2018 / Accepted: 21 November 2018 / Published: 5 January 2019

\begin{abstract}
Electrochemical jet milling (EJM) has broad prospects in engineering applications, its flexibility and versatility offering distinct advantages over traditional electrochemical machining (ECM). In the EJM process, the breakdown time of the passive film plays an important role in the selection of processing parameters. The Ti-6Al-4V (TC4), has been the most widely used titanium alloy in EJM in recent years. However, little research has been conducted on the breakdown time of the passive film on TC4. In this study, experiments concerning the breakdown behavior of the passive film on TC4 were conducted to investigate the influence of breakdown time on machining process in $\mathrm{NaNO}_{3}$ solution. Results showed that the breakdown time of the passive film stabilized at $0.58 \mathrm{~s}$ when the current density at the breakdown point exceeded $70 \mathrm{~A} / \mathrm{cm}^{2}$. For any point on the anode surface, the breakdown of the film occurred when the quantity of electric charge reached the point needed for breakdown. The effect of cathode feed rate on the EJM process was also investigated by simulation and experimentation. It was found that an increase of cathode feed rate could improve the machining quality. However, when the feed rate was increased to $50 \mathrm{~mm} / \mathrm{min}$, a large area of unbroken passive film remained on the anode surface. Based on systematic studies, a feed rate of between 3 and $12 \mathrm{~mm} / \mathrm{min}$ was judged to be optimal for the EJM process.
\end{abstract}

Keywords: Electrochemical jet milling; passive film; TC4 titanium alloy; breakdown behavior; cathode feed rate

\section{FULL TEXT}

(C) 2019 The Authors. Published by ESG (www.electrochemsci.org). This article is an open access article distributed under the terms and conditions of the Creative Commons Attribution license (http://creativecommons.org/licenses/by/4.0/). 
